\title{
Francesca Maria Crasta - Renzo Ragghianti, La biblioteca di Jehan Piochet de Salins e il Seigneur de la Montaigne
}

\section{Filippo Fassina}

\section{(2) OpenEdition \\ Journals}

\section{Edizione digitale}

URL: http://journals.openedition.org/studifrancesi/8879

DOI: 10.4000/studifrancesi.8879

ISSN: 2421-5856

\section{Editore}

Rosenberg \& Sellier

\section{Edizione cartacea}

Data di pubblicazione: 1 octobre 2008

Paginazione: 444

ISSN: 0039-2944

\section{Notizia bibliografica digitale}

Filippo Fassina, «Francesca Maria Crasta - Renzo Ragghianti, La biblioteca di Jehan Piochet de Salins e il Seigneur de la Montaigne», Studi Francesi [Online], 155 (LII | II) | 2008, online dal 30 novembre 2015, consultato il 10 janvier 2021. URL: http://journals.openedition.org/studifrancesi/8879 ; DOI: https:// doi.org/10.4000/studifrancesi.8879

Questo documento è stato generato automaticamente il 10 janvier 2021.

\section{cc) $($ ) $\ominus$}

Studi Francesi è distribuita con Licenza Creative Commons Attribuzione - Non commerciale - Non opere derivate 4.0 Internazionale. 


\title{
Francesca Maria Crasta - Renzo Ragghianti, La biblioteca di Jehan Piochet de Salins e il Seigneur de la Montaigne
}

\author{
Filippo Fassina
}

\section{NOTIZIA}

FRANCESCA MARIA CRASTA - RENZO RAGGHIANTI, La biblioteca di Jehan Piochet de Salins e il

Seigneur de la Montaigne, 2006 («Rinascimento», XLVI), pp. 403-477.

I Il presente studio offre una descrizione dettagliata della biblioteca personale della famiglia Piochet. Escludendo la documentazione prettamente giuridica e notarile peraltro ricchissima -, gli AA. concentrano la propria attenzione sul fatto che tale biblioteca, grazie a Jehan Piochet, divenne un vero e proprio «luogo simbolico di scambio» legato a un circolo erudito. Una parte del lavoro è consacrata all'analisi di una copia manoscritta della Servitude volontaire di Étienne de la Boétie, che pone notevoli problemi filologici, affrontati in questa sezione. Dall'esame complessivo dei titoli emerge una particolare predilezione dell'erudito per la storia, la geografia e la teoria politica. Non è trascurabile il filone magico-ermetico; inoltre ampio spazio è dato alla letteratura antica, specialmente a Cicerone e alla poesia greca. Da notare in appendice l'elenco completo delle opere presenti nella biblioteca, catalogate e divise per argomento in base alle indicazioni dello stesso Piochet. 